\title{
Relative Stabilization under Flexible and Dual Exchange Rate Regimes with Rational Expectations
}

\author{
Ching-chong Lai* and \\ Wen-ya Chang**
}

\begin{abstract}
Based on a rational expectations model, this paper analyzes the relation between wage indexation and the relative performance of macroshocks under the flexible regime versus dual regime with neutral intervention policy. The emphasis is on how the degree and type of wage indexation and the distinction between temporary and permanent disturbances affect the relative output variation under alternative exchange rates.
\end{abstract}

\section{Introduction}

Choice between exchange rate regimes has already been extensively debated in the literature. Most of the previous contributions (see, for examples, Chen (1975), Boyer (1978), Flood (1979), Weber (1981), Marston (1982)) to this topic have confined their analyses to the comparison between fixed and flexible exchange rates. A generally accepted conclusion from these papers is that when shocks are originated externally, flexible exchange rates are superior to fixed exchange rates, since the former has less output or price variation; if shocks are originated internally the reverse is true.

Recently, the enormous movement of capital across national borders, often a result of foreign exchange speculation, results in a great deal of instability in the international monetary system. After the collapse of the Bretton Woods System, many countries have adopted the regime of dual exchange rates. Under such a system, all current account transactions take place at a pegged commercial rate, while all capital account transactions take place at a freely floating financial rate. For the purpose of preventing current account imbalance from spreading to the domestic economy in this regime, the monetary

*Associate Research Fellow, Institute of the Three Principles of the People, Academia Sinica, and Asecciate Professor, Institute of Industrial Economics, National Central University. Taiwan. Republic of China.

**Lecturer, Department of Economics, Fu-Jen Catholic University, Taiwan, Republic of China. 
authorities may intervene in the financial foreign exchange market, and be engaged in neutral intervention operations. The neutral intervention policy has been defined by Lanyi (1975, p. 716): "the monetary authority sells (buys) foreign exchange in the financial exchange market equal to the net increase (loss) in official reserves arising from a current account surplus (deficit)." Thus, adds he (1975, p. 716), "a neutral intervention policy ensures overall balance of payments equilibrium, with the imbalance on current account exactly offset by an equal imbalance of opposite sign on capital account."

This paper attempts to examine the relative stabilization under flexible exchange rates versus dual exchange rates with neutral intervention policy after incorporating various wage indexation rules. The issue is chosen for the following reasons:

1. The existing studies on the internal or external disturbances to the domestic economy under dual exchange rates mostly focus their attention on a framework which is characterized by flexible financial rates and pegged commercial rates with nonintervention policy (for examples, Argy and Porter (1972), Dornbusch (1976), Marion (1981), Flood and Marion (1982), Cumby (1984), Aizenman (1985), Lai and Chu (1986a)], or by the financial and commercial rates both being flexible (for examples, Flood and Marion (1982), Bhandari (1985), Lai and Chu (1986b)]. Few have discussed the problem by using the framework of neutral intervention operations.

2. Under both exchange rate regimes, the overall balance of payments, which consists of the current and capital accounts, is maintained in equilibrium. The only difference between the two regimes is that the current account and capital account transactions are settled at different exchange rates under dual exchange rates, while the transactions in both accounts are settled at the same exchange rate under flexible exchange rates.

3. In order to escape from possible losses of purchasing power and cost of wage re-contracting, many industrial countries have linked their contracted wages to the domestic and foreign prices. ${ }^{2}$ As a result, many international monetary studies, including Salop (1974), Casas (1975)(1977), Purvis (1979), Sachs (1980), Marston (1982), Turnovsky (1983), Aizenman and Frenkel (1985) (1986) have replaced the sticky wage assumption of the simple Keynesian model with wage indexation. Among the authors, Marston (1982) examines the choice between fixed and flexible exchange rates by putting wage indexation into consideration, and concludes that, "the more highly indexed the economy, the less difference the choice of exchange rate regime makes for output variation." (p.103) Marston's finding gives us an advice that the choice of exchange rate regimes must take into account wage indexation.

1. This is the reason why Swoboda (1974,p.260) argues that, "such (neutral intervention) operations maintain the stock of international reserves constant, so that current-account imbalances do not affect the monetary base."

2. Fischer (1983) and Emerson (1983) offer a rich body of empirical evidence. 
The above points justify the inclusion of neutral intervention operations and wage indexation in our model. We will show that such an inclusion does have strong implications. In particular, we are able to show that the relative stabilization of fiscal and monetary disturbances under the flexible exchange regime versus dual exchange regime with neutral intervention operations will be contingent upon (1) the degree of wage indexation, (2) the type of wage indexation, (3) the degree of asset substitutability, (4) the relative size of expenditure-switching effect versus expenditure-reducing effect of devaluation, and (5) the property of the disturbances (i.e. , whether temporary, persistent, or permanent). Details of how these results are obtained are of course to be shown in the text, which will proceed as follows. Section II below proposes a general macro framework which is able to describe both flexible and dual exchange rate regimes. In section III the rational expectations solution to the model is outlined. Section IV,V and VI compare the variability of output for both regimes under various types of macroshocks. Finally, the main conclusions are reviewed in Section VII.

\section{The Model}

Consider an open economy that is "small" enough to regard the foreign price and interest rate as exogenously determined. Domestic production is limited to a single final commodity, part of which is consumed domestically, and the remainder is exported. Domestic consumers have access to both domestic good and imported good. These goods are regarded by domestic residents as imperfect substitutes. Without loss of generality, we set the foreign currency price of imports at unity. The economy can be characterized by the following $\log$-linear relationships :

$$
\begin{aligned}
& y_{t}=a_{0}+a_{1} y_{t}-a_{2}\left[r_{t}-\left({ }_{t}^{q} t+1-q_{t}\right)\right]+a_{3} g_{t}+a_{4}\left[h_{0}+h_{1}\left(e_{t}^{c-p_{t}}\right)-h_{2} y_{t}\right] \\
& a_{2}, a_{3}, a_{4}, h_{1}>0,1>a_{1}, h_{2}>0 \\
& m_{t}-q_{t}=b_{0}+b_{1} y_{t}-b_{2} r_{t} \quad b_{1}, b_{2}>0 \\
& {\left[h_{0}+h_{1}\left(e_{t}^{c}-p_{t}\right)-h_{2} y_{t}\right]+h_{3}\left\{\left(r_{t}-r_{t-1}\right)-\left(r_{t}^{*}-r_{t-1}^{*}\right)-r_{t}^{*}\left(e_{t}^{c}-e_{t}^{f}\right)\right.} \\
& \left.+r_{t-1}^{*}\left(e_{t-1}^{c}-e_{t-1}^{f}\right)-\left(e_{t}^{e} f_{t+1}^{-}{ }_{t-1} e_{t}^{f}\right)+\left(e_{t}^{f}-e_{t-1}^{f}\right)\right\}=0 \quad h_{3}>0 \\
& y_{t}=\lambda_{0}+\lambda_{1} p_{t}+\lambda_{2} t-1_{t}{ }+\lambda_{3 t-1} e_{t}^{c}+\lambda_{4} e_{t}^{c}
\end{aligned}
$$




$$
\begin{array}{lr}
q_{t}=\alpha e_{t}^{c}+(1-\alpha) p_{t} & 1>\alpha \geq 0 \\
g_{t}=\bar{g}+\mu_{t}^{g} & \\
\mu_{t}^{g}=p^{g} \mu_{t-1}^{g}+\underbrace{g}_{t} & 1 \geq p^{g} \geq 0 \\
m_{t}=\bar{m}+\mu_{t}^{m} & \\
\mu_{t}^{m}=p^{m} \mu_{t-1}^{m}+\varepsilon_{t}^{m} & \\
e_{t}^{c}=e_{t}^{f}=e_{t}, & \text { flexible exchange rates } \\
e_{t}^{c}=e^{-c}, & \text { dual exchange rates }
\end{array}
$$

with the exception of the domestic nominal interest rate $\mathrm{r}$ and the foreign nominal interest rate $r^{*}$, all variables are expressed in logarithms. The variables are defined as follows: $y=$ domestic real output $; q=$ general price level $; g=$ government expenditure $; e^{c}=$ commercial exchange rate (defined as the domestic currency price of foreign currency) : $p=$ domestic price level $m=$ nominal money supply $; e^{f}=$ financial exchange rate ( defined as the domestic currency price of foreign currency) ; ${ }_{j} X_{s}=$ expectation of variable $\mathrm{X}$ for time $\mathrm{s}$, based on information available at time $\mathrm{j} ; \overline{\mathrm{g}}=$ desired government expenditure $; \mu_{\mathrm{t}}^{\mathbf{g}}=$ fiscal disturbance $; \varepsilon_{\mathrm{t}}^{\mathbf{g}}=$ white noise fiscal disturbance $: \overline{\mathrm{m}}=$ desired nominal money supply; $\mu_{t}^{m}=$ monetary disturbance $; \varepsilon_{t}^{m}=$ white noise monetary disturbance. In addition, the subscript $\mathrm{t}$ refers to time.

Equation (1) is the equilibrium condition for the goods market. It specifies that aggregate demand is determined by the level of domestic output, the real interest rate, and the relative price of foreign to domestic good. Equation (2) is the equilibrium condition for the money market. The nominal money supply deflated by the general price indicates that part of the transaction demand for money is for imports [Turnovsky (1981a), (1981b)].

Equation (3) specifies that the overall balance of payments is the sum of the trade balance and net capital inflows. Following Driskill and McCafferty (1980), Driskill (1981), Turnovsky and Bhandari (1982) and Bhandari, Driskill and Frenkel (1984), we assume that the net stock demand for foreign bonds (defined as the difference between domestic demand for foreign bonds and foreign demand for domestic bonds), $\mathrm{B}_{\mathrm{t}}$, is a decreasing function of the difference between yield on domestic bonds, $r_{t}$, and that on foreign 
bonds,

$$
\begin{aligned}
& r_{t}^{*}+r_{t}^{*}\left(e_{t}^{c}-e_{t}^{f}\right)+\left({ }_{t} e_{t+I}^{f_{t}} e_{t}^{f_{t}}\right)^{3} \text { i.e., } \\
& \quad B_{t}=-h_{3}\left[r_{t}-r_{t}^{*}-r_{t}^{*}\left(e_{t}^{c}-e_{t}^{f}\right)-\left(r_{t} e_{t+1}-e f_{t}^{f}\right)\right]
\end{aligned}
$$

where the coefficient $h_{3}$ measures the degree of asset substitutability.

The increase (decrease) in the stock of $B_{t}$ reflects a net capital outflows (inflows) across the countries. Furthermore, both flexible regime and dual regime with neutral intervention operations ensure overall balance of payments equilibrium. Therefore, the equilibrium condition for the foreign exchange market under both regimes can be described by

$$
T_{t}=\Delta B_{t}
$$

where $T_{t}$ denotes balance of trade. Taking the first difference of equation(9) and recalling $T_{t}=h_{0}+h_{1}\left(\mathrm{e}_{\mathrm{t}}^{\mathrm{c}}-p_{t}\right)-h_{2} y_{t}$, equation (10) can be reduced to (3).

Aggregate supply function is specified by equation (4). The function is based on the nature of labor contract and wage indexation developed by Gray (1976), Fischer (1977) for a closed economy, and Sachs (1980), Marston (1982), Marion (1982), Turnovsky (1983) for an open economy. Equation (4) can be derived as follows:

In the short run, the aggregate output is a function of the quantity of labor employed, $e_{t}$ (expressed in logarithm),

$$
y_{t}=v_{0}+v_{1} e_{t} \quad 1>v_{1}>0
$$

Labor demand $e_{t}^{d}$ is derived by setting the marginal product of labor equal to the real wage in terms of the domestic price. Let $\mathrm{w}_{\mathrm{t}}$ denote the logarithm of money wages, the equality implies that

3. For detailed derivation, see Flood (1978), Gardner (1985), and Lai and Chu (1986b). It is worth noting that, under the flexible regime $\left(e_{t}^{c}=e_{t}^{f}=e_{t}\right)$, the return on foreign bonds reduces to $r^{*}+\left(t_{t} e_{t+1}-e_{t}\right)$.

4. Since this paper is chiefly interested in the relative stabilization of macroshocks under alternative exchange rates, we do not include a supply disturbance in the production function. The interaction between supply shocks and wage indexation is examined by Gray (1976). Fischer (1977), Karni (1983), Marston (1984), Marston and Turnovsky (1985), Aizenman and Frenkel (1985) (1986) and Turnovsky (1986). 


$$
v_{0}+\ln v_{1}-\left(1-v_{1}\right) e_{t}^{d}=w_{t}-p_{t}
$$

On the other hand, we assume that labor supply, $e_{t}^{s}$, is a positive function of real wage in terms of general price since workers consume both domestic and imported goods. Therefore, the labor supply function can be written as

$$
\mathrm{e}_{\mathrm{t}}^{\mathrm{s}}=c_{0}+c_{1}\left(w_{t}-q_{t}\right) c_{1}>0
$$

Following Turnovsky (1983), we assume nominal wages are determined in the following general manner

$$
w_{t}={ }_{t-1} w_{t}^{c}+k_{1}\left(p_{t}-{ }_{t-1} p_{t}\right)+k_{2}\left(e_{t}^{c}-{ }_{t-1} e_{t}^{c}\right) \quad 1 \geq k_{1}, k_{2} \geq 0
$$

where ${ }_{\mathrm{t}-1} w_{t}^{c}$ is the contract wage negotiated at time $t-1$ for time $t$ (expressed in logarithm), and $k_{1}$ and $k_{2}$ designate the degree of wage indexation to the domestic price and foreign price respectively. These indexation parameters are assumed to vary between 0 and 1 . Equation (14) can allow many special wage indexation schemes: (1) if $k_{1}>0$ and $k_{2}=0$, nominal wages are only indexed to the domestic price, with $k_{1}=1$ being full indexation; (2) if $\mathrm{k}_{1}=0$ and $\mathrm{k}_{2}>0$, nominal wages are only indexed to the foreign price, with $k_{2}=1$ being full indexation. (3) if $k_{1}=k(1-\alpha), k_{2}=k \alpha$,nominal wages are indexed to the general price, with $k=1$ being full indexation. Finally a less specific form than either of the three indexation rules stated above is that (4) nominal wages are said to be indexed to both the domestic price and foreign price if $k_{1}+k_{2}$ $<1$, with $k_{1}+k_{2}=1$ being full indexation. ${ }^{5}$

Since nominal wage contracts are negotiated at time $t-1$, we assume that the contract wage is determined by equating the expected labor demand with expected labor supply. Accordingly, from equations (12) and (13) it is easy to obtain that

$$
{ }_{t-1} w_{t}^{c}=\frac{1}{1+c_{1}\left(1-v_{1}\right.}\left[v_{0}+\ln v_{1}-c_{0}\left(1-v_{1}\right)+{ }_{t-1} p_{t}+\left(1-v_{1}\right) c_{1} t-1_{t}^{q}\right]
$$

The short-run actual quantity of labor traded is assumed to be determined by the quantity demanded, ${ }^{6}$ so let $e_{t}^{d}$ be equal to $e_{t}$, and combine (11), (12), (14) and (15), we obtain the aggregate supply function

5. Turnovsky (1983) presents a detailed explanation.

6. In an interesting paper, Cukierman (1980) assumes employment is determined by a weighted average of the quantity demanded and supplied. 


$$
y_{t}=\lambda_{0}+\lambda_{1} p_{t}+\lambda_{2} t-1^{p_{t}}+\lambda_{3} t-1_{t}^{c}+\lambda_{4} e_{t}^{c}
$$

Where $\lambda_{0}=v_{0}+\frac{v_{1}\left[c_{0}+c_{1}\left(v_{0}+\ln v_{1}\right)\right]}{1+c_{1}\left(1-v_{1}\right)}, \lambda_{1}=\frac{v_{1}\left(1-k_{1}\right)}{1-v_{1}}$,

$\iota_{2}=\frac{v_{1}\left\{c_{1}\left(1-v_{1}\right)\left[k_{1}-(1-\alpha)\right]-\left(1-k_{1}\right)\right\}}{\left(1-v_{1}\right)\left[1+c_{1}\left(1-v_{1}\right)\right]}, \lambda_{3}=\frac{v_{1}\left(k_{2}+c_{1}\left(1-v_{1}\right)\left(k_{2}-\alpha\right)\right]}{\left(1-v_{1}\right)\left[1+c_{1}\left(1-v_{1}\right)\right]}$ and

$\lambda_{4}=-\frac{v_{1} k_{2}}{1-v_{1}}$.

Equation (5) defines the general price to be a multiplicatively weighted average of the price of domestic and imported goods. Equations (6a) and (7a) specify government expenditure and money supply as consisting of deterministic and stochastic terms. Furthermore, equations (6b) and (7b) describe that the current stochastic components are generated by first-order autoregressive processes. If the autocorrelation parameter $p \&=p^{m}=0$, innovations $\varepsilon q$ and $\varepsilon_{t}^{m}$ are purely temporary. On the other hand, $p g=$ $p^{m=1}$ implies that innovations are permanent, and $1>p^{8}, p^{m}>0$ implies that innovations are persistent. ${ }^{7}$ Equation (8a) specifies that the current account and capital account transactions are settled at a uniform exchange rate under flexible exchange rates, while (8b) specifies that the current account transactions are settled at a pegged exchange rate under dual exchange rates.

\section{The Rational Expectations Solution}

Under flexible exchange rates, substitute (5), (6a), (6b), (7a), (7b), and (8a) into (1) - (4), the resulting four equations (1)-(4) determine four endogenous variables: $y_{t}, r_{t}, p_{t}, e_{t}$. Under dual exchange rates with neutral intervention policy, substitute (5), (6a), (6b), (7a), (7b), and (8b) into (1)-(4), the resulting four equations (1)(4) also determine four endogenous variables: $y_{t}, r_{t}, p_{t}, e_{t}^{f}$. Since the purpose of this

7. See Marion (1982) and Marston (1985, pp. 896-9). 
paper is to compare the relative output variation under alternative exchange rates in the presence of random disturbance, we must first derive the reduced-form solution for $y_{t}$ of the two regimes.

Let "flex" and "dual" denote flexible exchange rates and dual exchange rates respectively, and use the method of undetermined coefficient, the domestic output solutions under the two regimes are

$$
\begin{aligned}
& y_{t}^{\text {flex }}=\pi_{0}+\pi_{1} \mu_{t-1}^{g}+\pi_{2} \varepsilon_{t}^{g}+\pi_{3} \mu_{t-1}^{m}+\pi_{4} \varepsilon_{t}^{m} \\
& y_{t}^{\text {dual }}=\eta_{0}+\eta_{1} \mu_{t-1}^{g}+\eta_{2}^{\varepsilon} \varepsilon_{t}^{g}+\eta_{3} \mu_{t-1}^{m}+\eta_{4}^{\varepsilon} t_{t}^{m}
\end{aligned}
$$

where $\pi_{0}$ and $\eta_{0}$ are constants, $\pi_{1}=\left(1+b_{2}\right) p^{8}\left[a_{3}\left(\lambda_{1}+\lambda_{2}\right) h_{3}\right] / \Delta_{1}$.

$$
\begin{aligned}
& \pi_{2}=a_{3}\left\{\lambda_{1}\left[\alpha h_{3}+b_{2}\left(h_{1}+\left(1-p^{g}\right) h_{3}\right]+\lambda_{4}\left[b_{2} h_{1}-(1-\alpha) h_{3}\right]\right\} / \Delta_{2}, \pi_{3}=p^{m}\left(\lambda_{1}+\lambda_{2}\right) a_{2} h_{3} / \Delta_{1},\right. \\
& \pi_{4}=\left(\lambda_{1}+\lambda_{4}\right)\left[a_{2}\left(h_{1}+\left(1-p^{m}\right) h_{3}\right)-h_{3}\left(a_{2}\left(1-p^{m}\right) \alpha_{-}-a_{4} h_{1}\right)\right] / \Delta_{2}, \eta_{1}=p^{g}\left(a_{3} b_{2}\left(\lambda_{1}+\lambda_{2}\right)\right] / \Delta_{3}, \\
& \eta_{2}=a_{3} b_{2} \lambda_{1} / \Delta_{4}, \eta_{3}=p^{m}\left[a_{2}\left(\lambda_{1}+\lambda_{2}\right)\right] / \Delta_{3}, \eta_{4}=a_{2} \lambda_{1} / \Delta_{4}, \\
& \Delta_{1}=\left(\lambda_{1}+\lambda_{2}\right)\left[h_{3}\left(1-a_{1}+a_{4} h_{2}\right)\left(1+b_{2}\right)+a_{2}\left(h_{2}+b_{1} h_{3}\right)\right]+a_{2}\left((1-\alpha) h_{3}+h_{1}\right)+a_{4} h_{3} h_{1}\left(1+b_{2}\right), \\
& \Delta_{2}=\left[1+b_{2}(1-j)\right]\left\{a_{2} h_{1}+h_{3}\left[(1-\alpha) a_{2}\left(1-p^{i}\right)+a_{4} h_{1}\right]\right\} \\
& +\lambda_{1}\left[1+b_{2}\left(1-p^{j}\right)\right]\left(a_{2} h_{2}+h_{3}\left(1-a_{1}+a_{4} h_{2}\right)\right]-\left(\lambda_{1}+\lambda_{4}\right)\left\{\left(b_{2} h_{2}-b_{1} h_{3}\right)\left[(1-\alpha) a_{2}\left(1-p^{j}\right)+a_{4} h_{1}\right]\right. \\
& \left.+\left(1-a_{1}+a_{4} h_{2}\right)\left[h_{3}(1-\alpha)-b_{2} h_{1}\right]+a_{2}\left(h_{2}(1-\alpha)-b_{1} h_{1}\right]\right\}, \\
& \Delta_{3}=\left(\lambda_{1}+\lambda_{2}\right)\left[b_{2}\left(1-a_{1}+a_{4} h_{2}\right)+a_{2} b_{1}\right]+(1-\alpha) a_{2}+a_{4} h_{1} b_{2}, \\
& \Delta_{4}=\lambda_{1}\left[a_{2} b_{1}+b_{2}\left(1-a_{1}+a_{4} h_{2}\right)\right]+(1-\alpha) a_{2}+b_{2}\left[(1-\alpha)\left(1-p^{i}\right) a_{2}+a_{4} h_{1}\right] .
\end{aligned}
$$


The following three sections will use the results of equations (17) and (18) to evaluate the relative performance of macroeconomic shocks under the flexible regime versus dual regime with neutral intervention policy.

\section{Unanticipated and Temporary Disturbances}

An unanticipated, temporary increase in macroeconomic disturbances is characterized by $p^{i}=0$ and $\varepsilon_{t}^{i}>0(i=g, m)$. In order to evaluate the relative efficacy of macroshocks, we can substract $\pi_{2} \mid p g=0$ from $\eta_{2} \mid p g=0$ and $\pi_{4} \mid p^{m}=0$ from $\eta_{4} \mid p^{m}=0$. It is easy to show that

$$
\begin{aligned}
& {\left[\partial y_{t}^{\text {flex }} / \partial \varepsilon_{t}^{g} \mid p^{g}=0\right] \gtreqless\left[\partial y_{t}^{d u a l} / \partial \varepsilon_{t}^{g} \mid p^{g}=0\right] \quad \text { as } \quad \psi \phi \gtreqless 0} \\
& {\left[\partial y_{t}^{\text {flex }} / \partial \varepsilon_{t}^{m} \mid p^{m}=0\right] \sum\left[\partial y_{t}^{d u a l} / \partial \varepsilon_{t}^{m} \mid p^{m}=0\right] \text { as } \quad \phi \leqslant 0}
\end{aligned}
$$

where $\psi=\lambda_{1}\left(b_{1} h_{3}-b_{2} h_{2}\right)+(1-\alpha) h_{3}-b_{2} h_{1}$ and $\phi=\left(\lambda_{1}+\lambda_{4}\right)\left(\alpha a_{2}\left(1+b_{2}\right)-b_{2} a_{4} h_{1}\right)$

$-\lambda_{4} a_{2}\left(1+b_{2}\right)$

The results reported in (19) and (20) can be explained as follows : under dual exchange rates, after substituting equations (5)-(7) and ( $8 b)$ into (1), (2) and (4), we can solve three variables, $y_{t}, r_{t}$, and $\mathrm{p}_{t}$, from these three equations, because the last endogenous variable $e f_{t}^{f}$ does not enter any of the equations (1), (2) or (4). In contrast, under flexible exchange rates, the four equations (1)-(4) simultaneously determine four variables, $y_{t}, r_{t}, p_{t}$ and $e_{t}$. Thus, the flexible regime has an additional exchange rate induced effect in the total effect of the disturbance, $\varepsilon_{t}^{i}(i=g, m)$, on $y_{t}$ More specifically, the macroeconomic relationship between the two regimes can be expressed as 


$$
\begin{aligned}
\left\lceil\partial y_{t}^{\text {flex }} / \partial \varepsilon_{t}^{i} \mid p^{i}\right. & =0]=\left[\partial y_{t}^{d u a l} / \partial \varepsilon_{t}^{i} \mid p^{i}=0\right] \\
& +\left[\partial y_{t}^{d u a l} / \partial e^{-c} \mid p^{i}=0\right]\left[\partial e_{t}^{\text {flex }} / \partial \varepsilon_{t}^{i} \mid p^{i}=0\right]
\end{aligned}
$$

The second term on the right hand side of (21) is just the exchange rate induced effect, i.e. , the induced response of macroeconomic shocks via exchange rate changes. The exchange rate induced effect includes two components. The term $\left[\partial e_{t}^{f l e x} / \partial \varepsilon_{t}^{i} p^{i}=0\right]$ indicates how the shocks depreciate or appreciate the domestic currency, and $\left[\partial y_{t}^{d u a l}\right.$ $\left|\partial e^{-c}\right| p^{i}=0$ ] indicates how a depreciation of the domestic currency in $e^{-c}$ increases or decreases domestic output.

It can be easily derived that

$$
\begin{aligned}
& \operatorname{sgn}\left[\partial y_{t}^{d u a l} / \partial e^{-c} \mid p^{i}=0\right]=-\operatorname{sgn}[\phi] \\
& \operatorname{sgn}\left[\partial e_{t}^{f l e x} / \partial \varepsilon_{t}^{g} \mid p^{8}=0\right]=-\operatorname{sgn}[\psi] \\
& \operatorname{sgn}\left[\partial e_{t}^{f l e x} / \partial \varepsilon_{t}^{m} \mid p^{m}=0\right]=1
\end{aligned}
$$

Putting equations (22) $-(24)$ into equation (21), we have

$$
\begin{gathered}
\operatorname{sgn}\left\{\left[\partial_{t}^{f l e x} / \partial \varepsilon_{t}^{g} \mid p^{g}=0\right]-\left\lfloor\partial y_{t}^{d u a l} / \partial \varepsilon_{t} g \mid p^{B}=0\right]\right\} \\
=\operatorname{sgn}[\phi] . \operatorname{sgn}[\psi]=\operatorname{sgn}[\phi \psi] \\
\operatorname{sgn}\left\{\left[\partial y_{t}^{f l e x} / \partial \varepsilon_{t}^{m} \mid p^{m}=0\right]-\left\lfloor\partial y_{t}^{d u a l} / \partial \varepsilon_{t}^{m} \mid p^{m}=0\right]\right\}=-\operatorname{sgn}[\phi]
\end{gathered}
$$

Equation (25) and (26) confirm the results what we have reported in equations (19) and (20) and lead to the following conclusions:

FINDING 1 (BENCHMARK FINDING). If nominal wages are rigid and the monetary effect of devaluation is absent, monetary disturbances have more output variation under the flexible regime that under the dual regime; and fiscal disturbances have less output variation under the flexible regime than under the dual regime when the domestic and foreign bonds are highly substitutable.

When there is no wage indexation $\left(k_{1}=k_{2}=0\right)$ and the monetary effect of deva- 
-luation is absent $(\alpha=0)$, the sign of $\phi$ in equations (19) and (20) becomes

$$
\operatorname{sgn}\left[\phi\left(k_{1}=k_{2}=\alpha=0\right)\right]=\operatorname{sgn}\left[-b_{2} a_{4} h_{1}\right]=-1
$$

Substituting equation (27) into equations (19) and (20) yields

$$
\begin{aligned}
& {\left[\partial y_{t}^{\text {flex }} / \partial \varepsilon_{t}^{g} \mid p^{8}=0\right] \underset{2}{\gtrless}\left[\partial y_{t}^{\text {dual }} / \partial \varepsilon_{t}^{g} \mid p^{8}=0\right] \quad \text { as } \quad \psi \leq 0} \\
& {\left[\partial y_{t}^{f l e x} / \partial \varepsilon_{t}^{m} \mid p^{m}=0\right]>\left[\partial y_{t}^{d u a l} / \partial \varepsilon_{t}^{m} \mid p^{m=0} 0\right]}
\end{aligned}
$$

Equation (28) reveals that, for the fiscal shocks, the relative output variation between two regimes depends on the degree of asset substitutability $\left(\mathrm{h}_{3}\right)$. If asset substitutability is relatively high, the dual regime will dominate the flexible regime; otherwise, the flexible regime will dominate the dual regime. On the other hand, equation (29) states that, for the monetary shocks, the flexible regime has a greater output variation than the dual regime regardless of the degree of asset substitutability. In order to conveniently describe the relative performance of macroshocks under both regimes, in what follows we will name the relationship reported in (28) and (29) the benchmark finding. ${ }^{8}$ FINDING 2. If the nominal wages are fixed, whether the benchmark finding will hold depends crucially on the relative size of the expenditure-switching effect of devaluation versus the expenditure-reducing effect of devaluation.

In the absence of wage indexation $\left(k_{1}=k_{2}=0\right)$, the sign of $\phi$ in equations (19) and $(20)$ reduces to

$$
\operatorname{sgn}\left[\phi\left(k_{1}=k_{2}=0\right)\right]=\operatorname{sgn}\left[\alpha a_{2}\left(1+b_{2}\right)-b_{2} a_{4} h_{1}\right]
$$

8. The benchmark finding reminds us to reminisce Fleming's (1962) well-known proposition for comparing the relative performance of macroeconomic policies under fixed exchange rates versus flexible exchange rates: $f$ iscal policy is more effective in changing output under fixed exchange rates than under flexible exchange rates when capital is highly mobile, but this conclusion is reversed with low mobility of capital; while monetary policy is more effective in changing output under flexible exchange rates than under fixed exchange rates regardless of the degree of capital mobility. Although the benchmark finding is similar to the Fleming proposition, it is worth noting that Fleming's model is based on the flow specification of capital movements, while our model is based on the stock specification of capital movements. 
where $a_{2}\left(1+b_{2}\right) \geqslant b_{2} a_{4} h_{1}$ depending on whether the expenditure-reducing effect of devaluation is greater or less than the expenditure-switching effect. ${ }^{9}$ If the former effect surmounts the latter, equation (30) becomes

$$
\operatorname{sgn}\left[\phi\left(k_{1}=k_{2}=0\right)\right]=1
$$

Combining (30)* with (19) and (20) gives

$$
\begin{aligned}
& \left\lfloor\partial y_{t}^{\text {flex }} / \partial \varepsilon_{t}^{g} \mid p^{8}=0\right] \gtrless\left[\partial y_{t}^{d u a l} \partial \varepsilon_{t}^{g} \mid p^{B}=0\right] \quad \text { as } \quad \psi \gtrless 0 \\
& {\left[\partial y_{t}^{\text {flex }} / \partial \varepsilon_{t}^{m} \mid p^{m}=0\right]<\left[\partial y_{t}^{d u a l} / \partial \varepsilon_{t}^{m} \mid p^{m}=0\right]}
\end{aligned}
$$

Obviously, these results are exactly contrary to those reported in equations (28) and (29). Thus, the benchmark finding is not valid if the expenditure-reducing effect is greater than the expenditure-switching effect.

FINDING 3. If the money wages are completely indexed to the domestic price, macroeconomic shocks would have no impact on output under both regimes.

The nominal wages are completely indexed to the domestic price if $k_{1}=1$ and $k_{2}=$ 0 . As a result, the $\phi$ in equations (19) and (20) would be

$$
\phi\left(k_{1}=1, k_{2}=0\right)=0
$$

Consequently, it follows from (19), (20) and (33) that

$$
\left[\partial y_{t}^{f l e x} / \partial \varepsilon_{t}^{i} \mid p^{i}=0\right]=\left[\partial y_{t}^{d u a l} / \partial \varepsilon_{t}^{i} \mid p^{i}=0\right]=0 \quad i=g, m
$$

9. Following the convention in the existing literature (for examples, Chen (1973), Connolly and Taylor (1976), Lai and Chen (1984)), we define expenditure-reducing effect and expenditure-switching effect with rigid nominal wages (i.e., $k_{I}=k_{2}=0$ ) as follows. Under dual regime, $e_{t}^{c}=e^{-c}$, differentiation of equation

(1) with respect to $\bar{e}^{-c}$ yields

$$
\left(1-a_{2}+a_{4} h_{2}\right)\left(\partial y_{t}^{d u a l} / \partial e^{-c}\right)=-a_{2}\left\{\partial \delta_{t}^{d u a l} / \partial e^{-c}\right)+a_{4}\left(\partial\left(e^{-c}-p_{t}^{d u a l}\right) / \partial e^{-c}\right)
$$

where $\delta_{t}$ indicates domestic real interest rate at time $t$. The first and second term of the right hand side in the above equation define the expenditure-reducing effect and expenditure-switching effect respectively.

Then, given $p^{j}=0$ and $k_{1}=k_{2}=0$, it can be easily derived that

$$
\begin{aligned}
& -a_{2}\left(\partial \delta_{t}^{d u a l} / \partial e^{c} \mid p^{i}=0\right)+a_{4}\left(\partial\left(e^{c}-p_{t}^{d u a l}\right) / \partial e^{c} \mid p^{i}=0\right) \\
& =-\left(1-a_{2}+a_{4} h_{2}\right)\left(v_{1}\left(\alpha a_{2}\left(1+b_{2}\right)-b_{2} a_{4} h_{1}\right) /\left(1-v_{1}\right)\right\} / \Delta_{4}
\end{aligned}
$$


Hence, with the nominal wages being completely indexed to the domestic price, both fiscal shocks and monetary shocks have zero effect on output under both regimes. This result is not surprising at all in view of our aggregate supply function (equation (4)). Giving $k_{1}=1$ and $k_{2}=0$, equation (4) would reduce to $y_{t}=\lambda_{0}$ if disturbances are unanticipated and temporary. Therefore, macroeconomic shocks must have an identical zero effect on output under both regimes.

FINDING 4. If money wages are fully indexed to: (i) the foreign price: (ii) the general price: (iii) the domestic and foreign price, the benchmark finding would be reversed.

The cases $k_{1}=0$ and $k_{2}=1, k_{1}=1-\alpha$ and $k_{2}=\alpha, k_{1}+k_{2}=1$ describe full indexation with respect to the foreign price, the general price, and the domestic and foreign price respectively. As a result, the sign of $\phi$ in equations (19) and (20) now becomes

$\operatorname{sgn}\left[\phi\left(k_{1}=0, k_{2}=1\right)\right]=\operatorname{sgn}\left[\phi\left(k_{1}=1-\alpha, k_{2}=\alpha\right)\right]=\operatorname{sgn}\left[\phi\left(k_{1}+k_{2}=1\right)\right]=1$

Substituting (35) into (19) and (20), inequalities (19) and (20) now reduce to

$$
\begin{aligned}
& {\left[\partial y_{t}^{\text {flex }} / \partial \varepsilon_{t}^{B} \mid p^{B}=0\right] \gtreqless\left[\partial y_{t}^{d u a l} / \partial \varepsilon_{t}^{g} \mid p^{B}=0\right] \quad \text { as } \quad \psi \gtreqless 0} \\
& {\left[\partial y_{t}^{\text {flex }} / \partial \varepsilon_{t}^{m} \mid p^{m}=0\right]<\left[\partial y_{t}^{d u a l} \partial_{t}^{m} \mid p^{m}=0\right]}
\end{aligned}
$$

Therefore, the benchmark finding would always be reversed if nominal wages are completely indexed to the following prices: (i) the foreign price ; (ii) the general price; and (iii) the domestic and foreign price. The economic interpretation of this finding is similar to that of the benchmark finding and need not be reelaborated here. FINDING 5. When the money wages are partially indexed to the domestic and foreign price, the key factors for the validity of the benchmark finding are: (i) the degree of wage indexation; (ii) the relative size of expenditure-switching effect versus expenditure-reducing effect of devaluation.

As mentioned above, the nominal wages are partially indexed to the domestic and foreign price when $0<k_{1}+k_{2}<1$. Then the sign of $\phi$ in (19) and (20) can be expressed explicitly by

$$
\operatorname{sgn}\left[\phi\left(1>k_{1}+k_{2}>0\right]=\operatorname{sgn}\left\{\left(1-k_{1}-k_{2}\right)\left[\alpha a_{2}\left(1+b_{2}\right)-b_{2} a_{4} h_{1}\right]+k_{2}\left(a_{2}+b_{2} a_{2}\right)\right\}\right.
$$


Combining (38) with (19) and (20), we can infer that the key factors for determining whether the benchmark finding will hold are: (i) the degree of domestic and foreign wage indexation $\left(k_{1}\right.$ and $\left.k_{2}\right)$; (ii) the relative size of the expenditure-switching effect versus the expenditure-reducing effect of devaluation $\left(\alpha a_{2}\left(1+b_{2}\right)-b_{2} a_{4} h_{1}\right) .^{10}$

\section{Unanticipated, Permanent or Persistent Disturbances}

The unanticipated disturbances are regarded permanent if $p^{i}=1, \varepsilon \underset{t}{i}>0$, or persistent if $1>p^{i}>0, \varepsilon_{t}^{i}>0(i=g, m)$. Under this situation, the relative stabilization of macroeconomic shocks can be reached by substracting $\pi_{2}$ from $\eta_{2}$ and $\pi_{4}$ from $\eta_{4}$ in equations (17) and (18). It is easy to obtain that

$$
\begin{aligned}
& {\left[\partial y_{t}^{\text {flex }} / \partial \varepsilon_{t}^{g}\right] \gtrless\left[\partial y_{t}^{\text {dual }} / \partial \varepsilon_{t}^{g}\right] \quad \text { as } \quad \psi \Omega_{\mathrm{g}} \gtreqless 0} \\
& {\left[\partial y_{t}^{\text {flex }} / \partial \varepsilon_{t}^{m}\right] \gtreqless\left[\partial y_{t}^{\text {dual }} / \partial \varepsilon_{t}^{m}\right] \text { as } \quad \Omega_{m} \lesseqgtr 0}
\end{aligned}
$$

where $\Omega_{i}=\left(\lambda_{1}+\lambda_{4}\right)\left[\alpha a_{2}\left(1+b_{2}\left(1-p^{i}\right)\right)-b_{2} a_{4} h_{1}\right]-\lambda_{4} a_{2}\left(1+b_{2}\left(1-p^{i}\right)\right), i=g, m$.

Obviously, $\Omega_{i}$ in equations (39) and (40) is very similar to $\phi$ in equations (19) and (20) except for the appearance of $p i$. Thus, the conclusions obtained in Section IV will remain valid after minor amendment. In addition, the following interesting findings can be obtained.

FINDING 6. If the nominal wages are partially indexed to the domestic and foreign price, the higher is the coefficient of persistence of macroeconomic shocks, the more likely will the benchmark finding remain true.

The case $1>k_{1}+k_{2}>0$ represents partial indexation to the domestic and foreign price. Then, the sign of $\Omega_{i}$ becomes

$$
\begin{aligned}
\operatorname{sgn}\left[\Omega_{i}\left(1>k_{1}+k_{2}>0\right)\right]= & \operatorname{sgn}\left[\left(1-k_{1}-k_{2}\right)\left(a_{2}\left(1+b_{2}\left(1-p^{i}\right)\right)-b_{2} a_{4} h_{1}\right)\right. \\
& \left.+k_{2} a_{2}\left(1+b_{2}\left(1-p^{i}\right)\right)\right]
\end{aligned}
$$

10. See footnote 9 
Hence, as long as $1>k_{1}+k_{2}>0$, the higher the $p^{i}$, the more likely the sign of $\Omega_{i}$ will be negative. Then, it follows from (39) and (40) that more likely will the benchmark finding be valid."

FINDING 7. If the money wages are completely indexed to any price, then no matter what value the coefficient of macroeconomic shocks takes, the benchmark finding will not be upheld.

Putting the appropriate values of $k_{1}$ and $k_{2}$ which correspond to various rules into $\Omega_{i}$, we can obtain that

$$
\begin{aligned}
& \operatorname{sgn}\left[\Omega_{i}\left(k_{1}=0, k_{2}=1\right)\right]=\operatorname{sgn}\left[\Omega_{i}\left(k_{1}=1-\alpha, k_{2}=\alpha\right)\right]=\operatorname{sgn}\left[\Omega_{i}\left(k_{1}+k_{2}=1\right]=1\right. \\
& \operatorname{sgn}\left[\Omega_{i}\left(k_{1}=1, k_{2}=0\right)\right]=0
\end{aligned}
$$

Thus, without the need to consider the magnitude of $p^{i}$, we can definitely infer that the benchmark finding is not.valid by substituting the results reported in (42) and (43) into (39) and (40).

\section{Anticipated Macroeconomic Shocks}

The case $p^{i} \neq 0$ and $\mu_{t-1}^{i}>0(\mathrm{i}=\mathrm{g}, \mathrm{m})$ represents an increase in the anticipated macroeconomic shocks. In order to compare the relative variation of macroeconomic shocks under the flexible versus dual regime, we substract $\pi_{1}$ from $\eta_{1}$ and $\pi_{3}$ from $\pi_{3}$ in (17) and (18) and obtain

$$
\begin{aligned}
& {\left[\partial y_{t}^{\text {flex }} / \partial \mu_{t-1}^{g}\right] \gtreqless\left[\partial y_{t}^{d u a l} / \partial \mu_{t-1}^{g}\right] \quad \text { as } \quad \xi \gtreqless 0} \\
& {\left[\partial y_{t}^{f l e x} / \partial \mu_{t-1}^{m}\right]<\left[\partial y_{t}^{d u a l} / \partial \mu_{t-1}^{m}\right]}
\end{aligned}
$$

where $\xi=\frac{\alpha v_{1} c_{1}}{1+c_{1}\left(1-v_{1}\right)}\left(b_{1} h_{3}-b_{2} h_{2}\right)+(1-\alpha) h_{3}-b_{2} h_{1}$.

The above results establish the following conclusions.

11. This finding remains true if the money wages are partially indexed to: (i) the domestic price: (ii) the foreign price: (iii) the general price. 
FINDING 8. The efficacies of anticipated stabilization policies have nothing to do with the degree of wage indexation under both regimes.

This finding is consistent with the result of rational expectations model and can be illustrated by focusing on the aggregate supply function. As described in Section II, the nominal wage contracts are negotiated by firms and labors at time $t-1$. At the same time, $\mu_{t-1}^{i}$ is anticipated by them and both unexpected change in the domestic price and exchange rate are equal to zero. Therefore, equation (14) reduces to $\mathrm{w}_{t}=$ $t-1 w_{t}^{c}$ and the aggregate supply function is independent of the wage indexation. In a frequently cited paper, Marston (1985, p. 898) makes a similar point.

FINDING 9. When macroeconomic policies are anticipated by the public, the benchmark finding will always be reversed.

As $\mu_{t-1}^{i}$ is completely anticipated by firms and labors at time $t-1$, the contracted wages, and hence current wages, will change with the change in domestic price and exchange rate expectations of both firms and labors. It follows equations (14) and (15) that

$$
\begin{aligned}
& d w_{t}=d_{t-1} w_{t}^{c}=\frac{1}{1+c_{1}\left(1-v_{1}\right.}\left[d_{t-1} p_{t}+\left(1-v_{1}\right) c_{1}\left[\alpha d_{t-1} e_{t}+(1-\alpha) d_{t-1} p_{t}\right]\right. \\
& =\frac{1+\left(1-v_{1}\right) c_{1}(1-\alpha)}{1+c_{1}\left(1-v_{1}\right)} d_{t-1} p_{t}+\frac{\left(1-v_{1}\right) c_{1}^{\alpha}}{1+c_{1}\left(1-v_{1}\right)} d_{t-1} e_{t}
\end{aligned}
$$

It is clear from (46) that the coefficients of $d_{t-1} p_{t}$ and $d_{t-1} e_{t}$ happen to sum to one.

On the other hand, if macroeconomic policies are unanticipated and temporary $\left(d_{t-1} w_{t}^{c}=d_{t-1} p_{t}=d_{t-1} e_{t}=0\right)$, and the degree of wage indexation corresponding to the domestic price and foreign price is $k_{1}=\frac{1+\left(1-v_{1}\right) c_{1}(1-\alpha)}{1+c_{1}\left(1-v_{1}\right)}, k_{2}=\frac{\left(1-v_{1}\right) c_{1}^{\alpha}}{1+c_{1}\left(1-v_{1}\right)}$ then from equations (14) and (15) we obtain

$$
d w_{t}=\frac{1+\left(1-v_{1}\right) c_{1}(1-\alpha)}{1+c_{1}\left(1-v_{1}\right)} d p_{t}+\frac{\left(1-v_{1}\right) c_{1} \alpha}{1+c_{1}\left(1-v_{1}\right)} d e_{t}
$$

Comparing (46) with (47), we can infer that so long as $d_{t-1} p_{t}=\mathrm{dp}_{t}, d_{t-1^{e}}=$ $\mathrm{de}_{\mathrm{t}}$, both cases will have the same result. This implies that the case of macroeconomic policies being anticipated by the public is similar to the case that macroeconomic policies 
are unanticipated and temporary with wages being fully indexed to the domestic price and foreign price. Therofore, we can be sure that in the latter case the benchmark finding will not hold, following the inference of FINDING 4.

\section{Concluding Remarks}

This paper has proposed a stochastic general macromodel of a small open economy under flexible exchange rates and dual exchange rates with neutral intervention policy. The emphasis is on how the degree and type of wage indexation and the distinction between temporary and permanent disturbances affect the relative output variation under the alternative regimes. We begin by examining the effects of the unanticipated and temporary disturbances in the case where the money wages are rigid and the monetary effect of devaluation is absent. The primary result that emerges from this situation is that, as domestic economy experiences monetary disturbances, dual exchange rates are usually preferable to flexible exchange rates from the viewpoint of domestic output stability since the former regime has less output variation than that of the latter regime regardless of the degree of asset substitutability. By contrast, as domestic economy experiences fiscal disturbances, the relative superiority between the two regimes depends crucially on the degree of asset substitutability since the flexible regime have less output variation than that of the dual regime if domestic and foreign bonds are highly substitutable, but this conclusion is reversed with low asset substitutability. In order to conveniently compare the relative output variation between the two regimes under other cases, throughout the paper we name this primary result the benchmark finding. We then evaluate the benchmark finding under various situations, the other important findings emerge from this analysis are :

(i) If macroeconomic shocks are unanticipated and temporary, the benchmark finding is always invalid if the money wages are fully indexed (to any price). However, the benchmark finding may hold if the money wages are partially indexed. The key factors for the validity of the benchmarke finding are: (1) the degree of wage indexation ; (2) the relative size of expenditure-switching effect versus expenditure-reducing effect of devaluation.

(ii) If the money wages are partially indexed (to any price), the stronger the degree of persistence of macroeconomic shocks is, the more likely will the benchmark finding remain valid; while if the money wages are completly indexed (to any price), no matter to what degree the macroeconomic shocks are persistent, the benchmark finding is always invalid. 
(iii) If macroeconomic shocks are anticipated by the public, the benchmark finding no longer holds.

\section{References}

Aizenman, Joshua. "Adjustment to Monetary Policy and Devaluation under Two-Tier and Fixed Exchange Rate Regimes, " Journal of Development Economics, MayJune, 1985, 18, pp. 153-69.

Aizenman, Joshua and Frenkel, Jacob A. "Optimal Wage Indexation, Foreign Exchange Intervention, and Monetary Policy," American Economic Review, June, 1985, 75, pp. 402-23.

Aizenman, Joshua and Frenkel, Jacob A. "Supply Shocks, Wage Indexation and Monetary Accommodation," Journal of Money, Credit, and Banking, August, 1986, 18, pp. 304-22.

Argy, Victor and Porter, Michael G. "The Forward Exchange Market and the Effects of Domestic and External Disturbances under Alternative Exchange Rate System, " IMF Staff Papers, November, 1972, 19, pp. 503-32.

Bhandari, Jagdeep S. "A Look at 'Overshooting' in a Two-Tier Float Exchange Rate System," Economics Letters, 1985, 19, pp. 57-61.

Bhandari, Jagdeep S., Driskill, Robert A. and Frenkel, Jacob A. "Capital Mobility and Exchange Rate Overshooting, " European Economic Review, April, 1984, 24, pp. 30920.

Boyer, Russel S. "Optimal Foreign Exchange Intervention," Journal of Political Econo$m y$, December, 1978, 86, pp. 1045-55.

Casas, Francisco R. "Efficient Macroeconomic Stabilization Policies under Floating Exchange Rates, " International Economic Review, October, 1975, 16, pp. 683-98.

Casas, Francisco R. "Capital Mobility and Stabilization Policies under Flexible Exchange Rates: A Revised Analysis, " Southern Economic Journal, April, 1977, 43, pp. $1528-37$.

Chen, Chau - nan. "The Monetary Effect of Devaluation: An Alternative Interpretation of the Cooper Paradox," Western Economic Journal, December, 1973, 11, pp. 475-80.

Chen, Chau-nan. "Fixed Versus Flexible Exchange Rates: A Reservoir Simile," Journal of Monetary Economics, 1975, 1, pp. 265-71.

Connolly, Michael and Taylor, Dean. "Adjustment to Devaluation with Money and Nontraded Goods," Journal of International Economics, August, 1976, 6, pp. 289-98.

Cukierman, Alex. " The Effects of Wage Indexation on Macroeconomic Fluctuation : 
A Generalization, " Journal of Monetary Economics, April, 1980, 6, pp. 147-70. Cumby, Robert E. "Monetary Policy under Dual Exchange Rates," Journal of International Money and Finance, August, 1984, 3, pp. 195-208.

Dornbusch, Rudiger. "The Theory of Flexible Exchange Rate Regimes and Macroeconomic Policy," Scandinavian Journal of Economics, May, 1976, 78, pp. 255-75.

Driskill, Robert A. "Exchange Rate Overshooting, the Trade Balance, and Rational Expectations, " Journal of International Economics, August, 1981, 11, pp. 361-77. Driskill, Robert A. and McCafferty, Stephen A. "Exchange Rate Variability, Real and Monetary Shocks, and the Degree of Capital Mobility under Rational Expectations," Quarterly Journal of Economics, November, 1980, 95, pp. 575-86.

Emerson, Michael. "A Review of Current European Indexation Experience," in Rudiger Dornbusch and Mario H. Simonson eds., Inflation, Debt, and Indexation, Cambridge, Mass. : MIT Press, pp. 160-79.

Fischer, Stanley. "Wage Indexation and Macroeconomic Stability," in Karl Brunner and Allan H. Meltzer, eds., Stabilization of the Domestic and International Econom$y$, Vol. 5 of the Carnegie-Rochester Series on Public Policy, Amsterdam: North -Holland, 1977, pp. 107-48.

Fischer, Stanley. "Indexing and Inflation," Journal of Monetary Economics, November, 1983, 12, pp. $519-42$.

Fleming, John M. “Domestic Financial Policies under Fixed and Floating Exchange Rates," IMF Staff Papers, November, 1962, 9, pp. 369-79.

Flood, Robert P. "Exchange Rate Expectations in Dual Exchange Markets," Journal of International Economics, February, 1978, 8, pp. 65-77.

Flood, Robert P. "Capital Mobility and the Choice of Exchange Rate System," International Economic Review, June, 1979, 20, pp. 405-16.

Flood, Robert P. and Marion, Nancy P. "The Transmission of Disturbance under Alternative Exchange Rate Regimes with Optimal Indexing," Quarterly Journal of Economics, Feburary, 1982, 97, pp. 43-66.

Gardner, Grant W. "Money, Price, and the Current Account in a Dual Exchange Rate Regime," Journal of International Economics, May, 1985, 18, pp. 321-38.

Gray, Jo Anna. "Wage Indexation: A Macroeconomic Approach," Journal of Monetary Economics, April, 1976, 2, pp. 221-35.

Karni, Edi. "On Optimal Wage Indexation," Journal of Political Economy, April, 1983, 91, pp. 282-92.

Lai, Ching-chong and Chen, Chau-nan. "Flexible Exchange Rates, Tight Money Effects, and Macroeconomic Policy," Journal of Post Keynesian Economics, Fall, 1984, 7 , pp. $128-33$. 
Lai, Ching-chong and Chu, Yun-peng. "Adjustment Dynamics under Dual Exchange Rates," Journal of International Economic Integration, Autumn, 1986a, 1, pp. 18393.

Lai, Ching-chong and Chu, Yun-peng. "Exchange Rate Dynamics under Dual Floating Exchange Rate Regimes," Southern Economic Journal, October, 1986b, 52, pp. 502-8.

Lanyi, Anthony. "Separate Exchange Markets for Capital and Current Transactions," IMF Staff Papers, November, 1975, 22, pp. 714-49.

Marion, Nancy p. "Insulation Properties of a Two-Tier Exchange Markets in a Portfolio Model," Economica, February, 1981, 48, pp. 61-70.

Marion, Nancy P. "The Exchange-Rate Effects of Real Disturbances with Rational Expectations and Variable Terms of Trade," Canadian Journal of Economics, February, 1982, 15, pp. 104-18.

Marston, Richard C. "Wages, Relative Prices, and the Choice between Fixed and Flexible Exchange Rates," Canadian Journal of Economics, February, 1982, 15, pp. 87-103. Marston, Richard C. "Real WAges and the Terms of Trade," Journal of Money, Credi$t$, and Banking, August, 1984, 16, pp. 285-301.

Marston, Richard C. "Stabilization Policies in Open Economies," in Ronald W. Jones and Peter B. Kenen, eds., Handbook of International Economics, Vol. II. Amsterdam : Elsevier Science Publishers B. V., 1985, pp. 859-916.

Marston, Richard C. and Turnovsky, Stephen J. "Imported Materials Prices, Wage Policy, and Macro-Economic Stabilization," Canadian Journal of Economics, May, 1985, 18, pp. $273-84$.

Purvis, Douglas D. "Wage Responsiveness and the Insulation Properties of a Flexible Exchange Rate," in Assar Lindbeck. ed., Inflation and Employment in Open Economies, Amsterdam: North-Holland, 1979, pp. 25-45.

Sachs, Jeffrey. "Wages, Flexible Exchange Rates, and Macroeconomic Policy," Quarterly Journal of Economics, June, 1980, 94, pp. 731-47.

Salop, Joanne. "Devaluation and the Balance of Trade under Flexible Wages," in George Horwich and Paul A. Samuelson, eds., Trade, Stability and Macroeconomics, New York: Academic Press, 1974, pp. 129-51.

Swoboda, Alexander K. "The Dual Exchange-Rate System and Monetary Independence," in Robert z. Aliber, ed., National Monetary Policies and the International Financial System, Chicago : University of Chicago Press, 1974, pp. 258-70.

Turnovsky, Stephen J. "The Effect of Devaluation and Foreign Price Disturbances under Rational Expectation," Journal of International Economics, February, 1981a, 11, pp. $33-60$. 
Turnovsky, Stephen J. "Monetary Policy and Foreign Price Disturbances under Flexible Exchange Rates: A Stochastic Approach," Journal of Money, Credit, and Banking, May, 1981b, 13, pp. 156-76.

Turnovsky, Stephen J. "Wage Indexation and Exchange Market Intervention in a Small Open Economy," Canadian Journal of Economics, November, 1983, 16, pp. 57492.

Turnovsky, Stephen J. "Supply Shocks and Optimal Monetary Policy," National Bureau of Economic Research, Working Paper No. 1988, July, 1986.

Turnovsky, Stephen J. and Bhandari, Jagdeep S. "The Degree of Capital Mobility and Stability of an Open Economy under Rational Expectations," Journal of Money, Credit, and Banking, August, 1982, 14, pp. 303-26.

Weber, Warren E. "Output Variability under Monetary Policy and Exchange Rate Rules," Journal of Political Economy, August, 1981, 89, pp. 733-51. 